\title{
LICENCIATURA EM EDUCAÇÃO DO CAMPO NA UFTM: ALGUMAS EXPERIÊNCIAS EM TEMPO-ESCOLA E TEMPO-COMUNIDADE
}

\author{
Daniervelin Renata Marques Pereira* \\ Verônica Klepka** \\ Juliano Pinheiro ${ }^{\star \star \star}$
}

RESUMO: Neste texto, busca-se o relato reflexivo de algumas experiências vivenciadas nos espaços Tempo-Escola e Tempo-Comunidade do curso de Licenciatura em Educação do Campo, da Universidade Federal do Triângulo Mineiro (UFTM). Tais experiências partem da proposta de se promover práticas de letramento baseadas na leitura e na escrita críticas da palavra e do mundo, de acordo com a proposta de Paulo Freire (2005). Para isso, propõe-se um percurso didático de produção de memórias das primeiras práticas de leitura e escrita dos educandos, associada a outras atividades que favorecem maior consciência das estratégias formais da escrita. Em Tempo-Comunidade, procura-se uma continuidade do percurso de leitura a partir da realidade da comunidade visitada. $A$ aliança entre diferentes áreas de conhecimento, representadas pelos docentes, é uma tentativa de se lançar sobre os sujeitos, tempos e espaços e olhares diferentes, que podem, assim, contemplar a pluralidade do contexto encontrado.

Palavras-chave: Educação do Campo; Letramento; Tempo-Escola e TempoComunidade.

\begin{abstract}
In this paper, we aim a reflexive description of some experiences lived in the environment Time-School and Time-Community of the Degree in Rural Education in the Federal University of Triângulo Mineiro (UFTM). Such experiences begin with the proposal of promoting literacy practices based on the critical reading and writing of the word and the world, according to the proposal of Paulo Freire (2005). For this, we propose a didactic production route of memories of the first reading and writing practices of the students, combined with other activities that promote greater awareness of formal strategies in writing. In Time-Community, the route of reading based on the reality of the community visited must be followed. The alliance between two different areas of knowledge represented by the professors, is an attempt to shed different looks on the subjects, times and spaces, which can thus contemplate the plurarity of the context found.
\end{abstract}

Keywords: Land-related Education; Literacy; Time-School; Time-Community.

\footnotetext{
* Doutora em Letras pela Universidade de São Paulo (USP). Docente da Universidade Federal do Triângulo Mineiro (UFTM). E-mail: daniervelin@gmail.com

** Doutoranda em Educação para a Ciência pela Universidade Estadual de Maringá (UEM). Docente da Universidade Federal do Triângulo Mineiro (UFTM). E-mail: veronicaklepka@gmail.com

${ }^{* * *}$ Doutorando em Ensino de Química pela Universidade Federal de Uberlândia (UFU). Docente da Universidade Federal do Triângulo Mineiro (UFTM). E-mail: pinheiro.js@gmail.com
} 


\section{INTRODUÇÃO}

O processo de instituição de cursos de Licenciatura em Educação do Campo se iniciou no Brasil em 2004 na Universidade Federal de Minas Gerais por demanda do Movimento dos Trabalhadores Rurais Sem Terra (MST), segundo Antunes-Rocha (2009, p. 39). A criação dessa nova modalidade data de 2007, quando se estabelece o Programa de Apoio às Licenciaturas em Educação do Campo - Procampo, vinculado à Secretaria de Educação Continuada, Alfabetização e Diversidade - Secad, do Ministério da Educação (MOLINA; SÁ, 2011, p. 13). O objetivo do Programa é apoiar a implementação de cursos regulares de Licenciatura em Educação do Campo nas Instituições Públicas de Ensino Superior de todo o país, voltados especificamente para a formação de educadores para a docência nos anos finais do Ensino Fundamental e no Ensino Médio em escolas do campo.

O curso de Licenciatura em Educação do Campo (LECampo) traz como marca o regime de alternância entre o Tempo-Escola (período de atividades na universidade) e o Tempo-Comunidade (período de atividades nas comunidades de origem dos educandos). Portanto, a sala de aula da LECampo vai além de uma determinada sala física na universidade, ganhando contornos mais amplos, geográfica, social, política e culturalmente. Assim, a interação começa na universidade e se estende às comunidades na tentativa de atender às demandas específicas de trabalho desse público (professores ou outros profissionais de educação, público jovem e adulto residente em comunidades do campo) e dialogar com os contextos desses educandos do curso.

Como desdobramento desse cenário, a partir de 2012, o MEC, via SECADI, lançou edital de livre concorrência para as universidades federais e o projeto da LECampo da Universidade Federal do Triângulo Mineiro foi aprovado e o curso implantado no campus Uberaba, em duas habilitações: áreas de Ciências da Vida e da Natureza e Matemática. O início das aulas ocorreu no segundo semestre de 2014. Ressaltamos que as atividades das disciplinas cursadas no primeiro Tempo- 
Escola (julho/2014) ocorreram com a presença dos professores das seguintes áreas: Língua Portuguesa, Matemática, Química e Tecnologias, buscando-se maior interação entre as áreas e os sujeitos envolvidos nas experiências do curso.

Neste texto, dedicamo-nos ao relato de algumas experiências vivenciadas nos primeiros Tempo-Escola (TE) e Tempo-Comunidade (TC) da LECampo, acompanhado de reflexões.

\section{PRÁTICAS DE LETRAMENTO NA LECampo/UFTM}

As atividades relatadas a seguir ocorreram em períodos de quatro horas, entre os dias 7 a 11 de julho de 2014, em uma turma de 21 licenciandos, inscritos na disciplina "Leitura e Escrita de Textos" (30h/a) no primeiro semestre do curso Licenciatura em Educação do Campo/UFTM. Os educandos apresentavam perfil diverso, sendo a maioria professores da Educação Básica e alguns agricultores e militantes de Movimentos de Trabalhadores Sem Terra.

Abaixo, descrevemos uma sequência de atividades propostas no contexto da disciplina "Leitura e Escrita de Textos":

1) Leitura e produção de sentidos na leitura do mundo e da palavra, a partir da leitura e discussão coletiva do texto "A importância do ato de ler", de Paulo Freire. Questões linguísticas, textuais e conceituais são tratadas em sala conforme necessidade apresentada pelo grupo. Em seguida, os educandos são convidados a escrever suas memórias, sendo cada um seu próprio leitor. Essa estratégia visou a mais liberdade de escrita.

2) Leitura de um cordel, retextualização e reescrita de memórias. Lemos coletivamente o cordel "Cante lá que eu canto cá", de Patativa do Assaré, e percebemos a apropriação da oralidade como elemento poético em textos literários. Distribuição das estrofes entre os educandos para uma atividade de "tradução" do poema para o registro formal. Reescrita das memórias após essa experiência de adequação. 
3) Leitura de imagens, revisão e reescrita de memórias. Após apresentação e discussão de fotografias de Sebastião Salgado, buscamos relacionar a fotografia de uma Sem Terra à sua história em forma de carta. Reescrevemos então coletivamente a carta, adequando-a ao registro formal. Por fim, retomamos as memórias de cada um com "olhar" revisor e tendo como destinatário os professores.

4) Atividades impressas desenvolvidas para o Tempo-Comunidade. O texto das memórias foi devolvido aos autores com sugestões de alteração. Foram propostas ainda atividades com produções textuais diversas (poemas, comentários, atividade de revisão, leitura de cartuns, análise didática, leituras diversas, exercícios gramaticais).

A proposta por trás da sequência dessas quatro atividades consistiu no transitar do oral para o escrito, proporcionando contato com textos que permitissem discussões sobre as modalidades fala e escrita, registro informal e formal. É importante mencionar que antes das atividades houve uma discussão sobre os preconceitos em torno da oposição certo x errado na língua (e também em outros contextos), termos que substituímos por adequado x inadequado de acordo com determinada situação comunicativa. A fala de um juiz em situação típica em uma audiência, por exemplo, é formal e seria inadequado empregar um dialeto não-padrão da língua portuguesa se considerarmos a construção cultural do discurso jurídico. Da mesma forma, espera-se que um diálogo entre mãe e filho se manifeste em níveis de informalidade, como é comum em gêneros orais da esfera de atividade cotidiana. Para essa discussão, baseamo-nos nas concepções sociolinguísticas a partir de Bortoni (2008) e Bagno (2009).

Também a proposta foi pensada para acontecer gradativamente, em torno da atividade central de escrita pelos educandos de memórias de seus primeiros passos na leitura do mundo e da palavra. Inicialmente, o contato com um texto que traz memórias sobre o ato de ler de forma intensa, como o texto de Paulo Freire, buscou servir de inspiração e incentivo ao olhar crítico dos educandos, 
rompendo com o conceito de leitura apenas vinculado à palavra. No processo criativo da escrita inicial, os educandos não precisavam se restringir pela dificuldade em dar a suas memórias uma roupagem formal, de maneira que as ideias aflorassem naturalmente. Da segunda para a terceira versão das memórias, houve um trabalho mais formal de adequação das memórias para torná-las mais legíveis ao olhar do outro. Nesse processo de escrita e reescrita, algumas atividades relatadas no item 3), como retextualização e revisão, por exemplo, foram pensadas como exercícios para percepção da relação texto-contexto, nem sempre clara para os educandos. As dúvidas gramaticais surgiam no tratamento do texto e eram esclarecidas nesse contexto. Algumas atividades gramaticais mais específicas foram também enviadas como exercícios para o Tempo-Comunidade (tempo em que os educandos estão em suas comunidades, realizando algumas atividades com acompanhamento do professor).

Diante dessa proposta, buscamos contemplar as práticas sociais de letramento em sua pluralidade, sem desconsiderar a importância de que um espaço seja reservado na sala de aula para a circulação de textos literários ou não com marcas de oralidade e informalidade, já que fazem parte da maioria das práticas sociais em que os educandos estão envolvidos. Dessa forma, pretendemos estabelecer um espaço e um tempo de convivência com textos e reflexão sobre os contextos a que estão atrelados. Essas atividades foram, então, percebidas como experiências importantes para o autoconhecimento do sujeito e de sua inserção histórica na leitura (a partir das memórias), para o contato e a compreensão da fala e da escrita como práticas que são ajustáveis a situações comunicativas (retextualização de cordel, revisão de texto), para a experiência com a leitura como conceito dinâmico, que contempla outros sistemas semióticos (leitura do mundo, leitura de fotografias), para a compreensão linguística relacionada a um contexto de realização (estudo da gramática em/por meio de textos) e para o respeito à diversidade linguística e cultural (compreensão das variedades linguísticas e culturais como inerentes ao sistema da língua e da sociedade). 
Citamos a seguir alguns trechos das memórias que nos chegaram à mão a partir dessa sequência didática:

[...] A minha maior felicidade foi quando começamos a utilizar a cartilha, toda colorida, com letras grandes, as sílabas formavam famílias, onde as consoantes eram os pais e as vogais os filhos. Eram como uma família que passeavam, estudavam, brincavam entre outras atividades, e conforme a vida deles acontecia formavam-se as palavras, no final de cada atividade sempre havia uma diversão. [...]. (Joana) ${ }^{1}$

[...] Olho hoje com muito carinho os medos vividos no $1^{\circ}$ dia de aula e com isso compreendo cada aluno que chega os prantos na creche ou escolas. Ouço as histórias de algum patinho contada pela D. Maria das Graças Mendonça até hoje, talvez essa foi minha referência em me tornar contadora de histórias [...]. (Paula)

[...] Eu lembro muito pouco de como aprendi a ler as palavras. Lembro mais de como aprendi a ler o mundo, com minha mãe que não possuía a leitura da palavra, mas descrevia com maestria a realidade dura da luta pela sobrevivência. Antes mesmo de compreender os signos da escrita, já tinha que convencer as donas de casa da vila a comprar a banana, o tomate ou alface que eu oferecia pelas ruas, com uma bacia enorme sobre minha cabeça.[...]. A escola bancária veio depois. A cartilha "caminho suave" orientava a leitura da palavra-palavra e não da palavramundo. A professora Dona Lourdinha, carinhosa e dedicada como uma segunda mãe não despertava para a dicotomia entre a leitura da palavra e a realidade da comunidade. O sistema de alfabetização era uniforme, sem considerar as particularidades. Lembro também que eu era vizinho de Dona Vilma, professora do Mobral. Mobral era um sistema de alfabetização, do beabá, em que a professora era auxiliada por um aparelho de rádio, com transmissão a nível nacional. O curso era à noite. Dona Vilma me pedia para acompanhá-la até a escola e transportar o rádio, na ida e na volta. A aula era cansativa, muitos alunos faltavam, e eu ficava ansioso pra que ela terminasse rápido. (João)

Os três trechos apresentados permitem diferentes olhares e uma apreensão da realidade sócio-histórico-pedagógica dos sujeitos que aí se inscrevem. Ressaltamos aqui a menção à cartilha Caminho Suave, recorrente nas

\footnotetext{
${ }^{1}$ Os nomes são fictícios e os textos foram transcritos como na versão entregue ao professor.
} 
memórias e que sinaliza um contexto brasileiro específico de alfabetização de grande difusão entre 1948 a 1990 (SCHLICKMANN, 2001), conhecida como "alfabetização pela imagem". A manifestação de tal informação permite questionamentos como: qual método utilizo hoje em minhas aulas (já que a maioria dos alunos são professores de educação básica)? Em que ele se diferencia do que foi empregado em minha formação? Que tipos de influência a alfabetização nesse método deixou em meu processo de aprendizagem? Essas e outras questões podem auxiliar não só no autoconhecimento como na consciência do processo ensino-aprendizagem de uma forma mais contextualizada.

Notamos ainda na leitura desses trechos a força da memória afetiva, associada aos sentidos, como percebemos pela remissão a cores, formas, sensações, sentimentos e impressões. Essas lembranças são relidas criticamente pelos educandos-atores, os quais são colaborados pela leitura de Paulo Freire (2005), como percebemos pela presença de seus neologismos: "palavra-palavra" (leitura mais restrita, relacionada ao texto verbal) e "palavramundo" (leitura dinâmica e contextualida da palavra, relacionada às vivências). Além disso, é citada a expressão "educação bancária", em que cabe ao educando apenas ser depósito, arquivar informações (FREIRE, 1983).

Destacamos, por fim, a valorização da leitura de mundo de sujeitos que fizeram parte da formação dos educandos, como seus pais, que ocupam lugar de "mestres" nesse ato. Também ficam os grandes mestres da sala de aula, que não são presentificados nas próprias memórias, seja por pequenos gestos, mas que levaram, por exemplo, a influências nas escolhas profissionais.

Como resultado da produção dos próprios educandos, foi criado um mural em formato de árvore, cujas folhas tomaram a forma de "leituras da palavramundo", conforme Figura 1 a seguir. Produção esta que também foi objeto de apreciação de visitantes durante o primeiro evento realizado pelos docentes da LECampo da UFTM em Uberaba, ocorrido na primeira semana de dezembro de 2014, denominado I Seminário Temático Café do Campo. Nessa ocasião, as 
vivências de TE e TC emergiram na escrita das memórias e na oralidade, quando apresentaram as produções aos participantes.

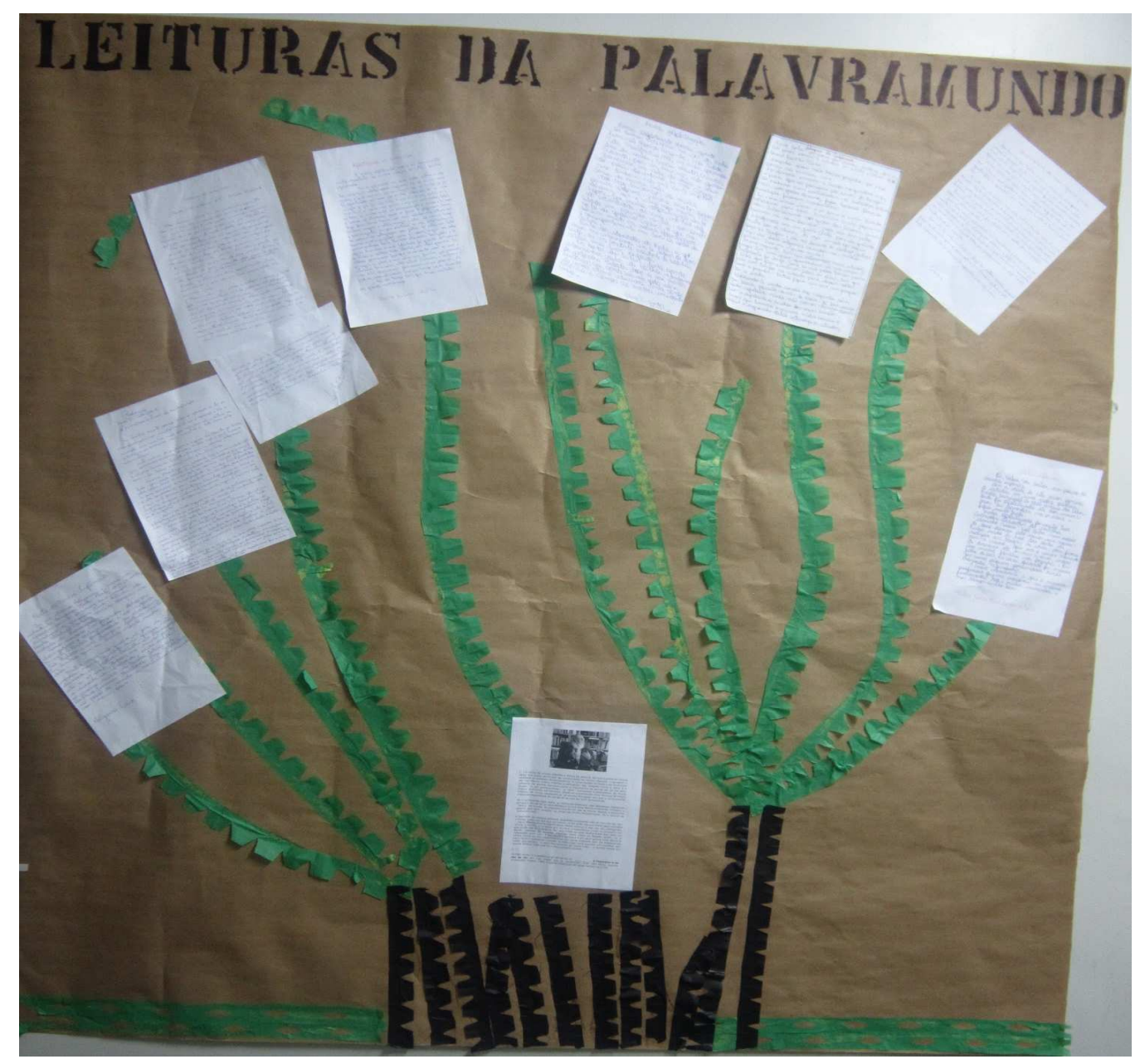

Figura 1: mural desenvolvido pelos educandos da $1^{a} \stackrel{a}{t}$ turma do curso LECampo/UFTM. Exposição durante o I Seminário Temático "Café do Campo".

Fonte: Foto dos autores.

\section{TEMPO-COMUNIDADE}

Já defendia Paulo Freire acerca da importância do homem, situado em seu espaço e tempo, a necessidade de tornar-se sujeito de sua própria história, agir sobre a realidade social de modo a transformá-la, interagir, comunicar, enfim, 
dialogar (FREIRE, 1974). Nessa perspectiva, o Tempo-Comunidade (TC) constituise em um instrumento para sistematizar e refletir sobre as ideias e práticas, problematizadas a partir da realidade vivida, fazendo emergir das comunidades de cada estudante da LECampo suas inquietações, seus problemas e sua realidade que são absorvidas pelas ações do docente e que transformam a Língua Portuguesa em um campo multi e interdisciplinar, promovendo leituras de mundos e causando o choque construtivo entre o território escolar e o território da vida.

$\mathrm{Na}$ ocasião do primeiro TC, visitamos a comunidade de três dos estudantes da LECampo. Situado no município de Campo Florido, o Assentamento Nova Santo Inácio Ranchinho é composto por pouco mais de uma centena de famílias de militantes do Movimento Sem Terra (MST). O local é composto por pequenas propriedades cujas atividades baseiam-se na criação de porcos, gado leiteiro, plantio de monoculturas e, principalmente, no arrendamento da terra para pastagem do gado ou plantio da cana de açúcar.

No primeiro dia do final de semana em que a primeira visita ocorreu (sábado, 16 de agosto de 2014), fomos recepcionados por várias famílias do assentamento, visita realizada com o objetivo de reconhecer as múltiplas dimensões dos espaços de vivência coletiva do assentamento, as questões ambientais, as problemáticas envolvendo os jovens, os trabalhadores e a comunidade em geral. $\mathrm{Na}$ ocasião, acompanhavam as ações de TC os professores de Língua Portuguesa, Química e Biologia.

Antunes-Rocha e Martins (2012) atentam para o fato de que essa ação de reconhecimento é uma das principais diferenças entre a escola comum e a Educação do Campo.

As questões ambientais, de inserção dos jovens, do trabalho, da saúde, dentre outras, são colocadas como temas que são discutidos e elaborados na comunidade, isto é, não cabe somente à escola a função de abordá-los. Esta talvez seja uma das principais rupturas que a organização em TE/TC traz para o processo formativo, pois há um impacto no papel da escola, notadamente naquela pensada para as classes populares (ANTUNES-ROCHA; MARTINS, 2012, p. 27). 
Muitos foram os temas que emergiram dessa visita de reconhecimento da comunidade e que devem fazer parte dos próximos encontros do TE em caráter interdisciplinar. Temas que ultrapassam o caráter pedagógico de reflexão e ação, exigindo posturas políticas e críticas, quebrando a cultura do silêncio, como diria Paulo Freire. Observamos que a questão ambiental é fortemente considerada pelos moradores do assentamento, como a falta da coleta de lixo e a escassa conscientização da comunidade, que dá origem a queimadas e aterro do lixo a seu modo.

Outras questões ligadas ao trabalho e produtividade da terra também foram destacadas. Algumas famílias mencionaram os problemas enfrentados com o cultivo de especiarias como a pimenta. Segundo eles, o alto custo de plantio, manutenção e colheita não era coberto pelo lucro das vendas, que eram pequenas e isoladas, visto que a comunidade não contava com parcerias para o transporte e o fornecimento do produto nos centros comerciais de cidades vizinhas. Muitas quantidades de pimenta foram perdidas pela falta de colheita a tempo ou armazenamento adequado, assim como todo o trabalho depositado.

Um dos grandes temas levantados refere-se ao conflito existente entre os moradores do assentamento no que diz respeito ao arrendamento de parte de suas terras para usinas de cana-de-açúcar. $O$ interesse e a necessidade do arrendamento por parte de alguns contrastam com as queixas de outros acerca dos inúmeros problemas ambientais causados por esse cultivo. Aqueles que não participam do arrendamento defendem outras formas de subsistência e exploração das terras, embora não tenham se organizado sistematicamente para refletir e praticar coletivamente essas formas.

Souza e Cleps Jr. (2009) retratam a expansão da cana-de-açúcar no Triângulo Mineiro e seus efeitos sobre a agricultura familiar e o trabalho rural. $\mathrm{Na}$ pesquisa, os autores analisam os desdobramentos dessas ações no Assentamento Nova Santo Inácio Ranchinho. Observou-se que houve uma grande expansão dessa monocultura no Triângulo Mineiro entre os anos de 2000 e 2007, sendo o Estado de Minas Gerais o terceiro maior produtor de cana-de-açúcar do 
país. São mais de 40 bilhões de toneladas colhidas somente na safra de 2008/2009, principalmente destinada à produção de etanol. O Brasil tornou-se um dos maiores exportadores da cana-de-açúcar a nível mundial, e diante das adequadas condições naturais de solo e clima, o Triângulo Mineiro passou a ser alvo das usinas, que concentram 73\% de sua produção em Minas Gerais.

Como reflexo do interesse político e manipulatório de garantir combustíveis alternativos, assegurar abastecimento energético e a exportação de álcool, áreas utilizadas como pastagem e cultivo de soja foram aos poucos sendo substituídas por lavouras de cana-de-açúcar, problemática vivenciada também pelo assentamento Santo Inácio Ranchinho, em Campo Florido.

O arrendamento trouxe consigo não só a ilusão de uma remuneração mensal segura aos trabalhadores rurais do assentamento como também, teoricamente, a subsistência familiar. Esses arrendamentos, contrários às regras da Reforma Agrária, mas autorizados pela Superintendência Regional do INCRA para o local, retirou muitos homens da produção de leite e cultivo familiar, submetendo-os a trabalhos como operadores de máquinas de plantio e colheita, sem sequer uma preparação. A renda obtida, pouco mais de $\mathrm{R} \$ 700,00$ (SOUZA; CLEPS JR., 2009), não compensa o desgaste físico, mental e da saúde de muitos desses trabalhadores, que antes do arrendamento ocupavam suas terras com 0 cultivo de mandioca, abóbora, pimenta, maracujá, produção de farinha e pecuária leiteira.

Portanto, para além dessas questões que se relacionam a outros aspectos sociais, políticos e culturais que os próprios licenciandos identificam, as demais famílias contrárias ao arrendamento justificam a degradação e o ressecamento das terras, o que as tornam improdutivas a outras atividades. Ao exporem esses problemas, os licenciandos expressam o interesse e demandam a ajuda dos professores e do próprio curso para o fortalecimento de suas ações, posicionamentos em defesa de suas ideias. Paralelamente à questão da cana, os licenciandos relataram que a comunidade do assentamento recebeu uma proposta para arrendamento das terras para exploração de biotecnologias por empresas 
internacionais, mas alegam não terem muitos detalhes sobre o assunto, embora desconfiem que seja pior do que a exploração de cana. Também pontuaram o arrendamento de pasto, realizado por algumas famílias, para gados de empresas privadas que prestam consultoria no assentamento.

No que diz respeito à educação, os licenciandos apresentaram queixas quanto a infraestrutura da única escola do assentamento. Alvo de furtos dias antes da nossa visita, a escola conta com poucas salas de aula e com pouco mais de 10 carteiras por sala. Mas a grande preocupação dos moradores é a evasão dos estudantes e a falta de professores da comunidade atuantes na escola, uma vez que os atuais professores da escola do campo, no assentamento, são de fora e não compreendem ou compartilham com as ideologias do movimento, a começar pelo posicionamento contrário à reforma agrária.

Como outro ponto evidenciado, os licenciandos da LECampo almejam a preparação para ações de orientação sexual na comunidade, visto que há muitos casos de gravidez na adolescência, o que acarreta o abandono dos estudos. Também relataram graves casos de abuso sexual na região e requerem orientação para lidar com esses problemas.

Como vimos, essas são algumas das questões que perpassam as demandas formativas de nossos licenciandos de Campo Florido, ânsias que podem ser as mesmas de outras comunidades, devendo ser também priorizadas na organização da prática em TE e TC. É nesses dois momentos e diferentes territórios que devem ser construídas mediações, diálogos, para se fortalecer os espaços de luta e transformação. Dessa forma, os sujeitos da escola e da comunidade podem atuar como agentes da profissão docente e do coletivo social (ANTUNES-ROCHA; MARTINS, 2012).

Após esse momento de investigação e reconhecimento das principais necessidades dos estudantes, deu-se início as atividades da disciplina-alvo dos encontros de 16 e 17 de agosto de 2014: "Leitura e Escrita de Textos". Contudo, a disciplina pautou-se na interdisciplinariedade com as outras áreas, já que aconteceu de forma mais intensa com a presença do professor de Química, e das 
professoras de Biologia e de Língua Portuguesa, pois a cada discussão várias questões que surgiam recebiam contribuições de todos os professores e licenciandos.

Trabalhamos, inicialmente, com os textos que os licenciandos escreveram no Tempo-Escola (memórias das leituras de mundo e da palavra de cada um). Fizemos marcações nos textos e eles propuseram uma reescrita. Eles também produziram um poema sob o tema "meus 12 anos", com base no poema de mesmo título de Chico Buarque. Assistimos ao filme "Narradores de Javé", que levou a discussões sobre a importância da escrita, da memória e várias relações da história com a vivência no assentamento (esses comentários vinham naturalmente, relacionados às vivências, como uma necessidade dos licenciandos). Discutimos um texto de divulgação científica ("Cientistas, engenheiros e artistas") e propusemos um debate formal entre os dois licenciandos que se dividiram, para uma atividade argumentativa, entre os dois pontos de vista do texto (saberes populares e saberes científicos). A ideia era desenvolver estratégias de argumentação oral e a fala formal. Como tarefa, eles ficaram com o livro "Quarto de despejo", de Carolina de Jesus, para ler e apresentar alguns trechos e ideias do texto e de suas opiniões aos colegas no próximo Tempo-Escola.

A experiência vivenciada pelos docentes e licenciandos do curso de licenciatura em Educação do Campo da UFTM, retratados neste estudo, partiu de uma lógica diferente da constituída e empregada pelo ensino atual. A integração social é uma das ações prezadas pela LECampo para a prática da liberdade que tem a expressão como perspectiva de tomada de consciência, identificação do lugar ocupado na sociedade, percepção e crítica dos processos vivenciados na sociedade industrializada. São, portanto, aspectos que afetam o campo, assim como as ações do campo têm suas influências para alavancar a sociedade. Por isso, completa Paulo Freire, 


\begin{abstract}
Mas qualquer que seja o grau a que se chegue, esta superação busca sempre uma apropriação da conjuntura por parte de seus atores. Aqueles que estão "conscientizados" se apoderam de sua própria situação, se inserem nela para transformá-la, pelo menos com seu projeto e com seus esforços (FREIRE, 1974, p. 84, tradução nossa).
\end{abstract}

Nesse espírito, ressaltamos, a educação desejada não pode ter como pretensão a neutralidade.

\title{
CONSIDERAÇÕES FINAIS
}

Apresentamos aqui um relato de leituras que se cruzam no contato entre os sujeitos em tempo-espaços educativos. Nesses tempo-espaços, buscamos criar situações de escrita coletiva, acreditando que assim podemos nos aproximar dos princípios citados por Antunes-Rocha (p. 366).

De forma resumida pode-se dizer que a Educação do Campo está comprometida com três princípios: o protagonismo dos sujeitos coletivos, a luta pela educação de qualidade e o compromisso com a construção do campo e da cidade como espaços de produção da vida de forma sustentável (ANTUNES-ROCHA, p. 366).

Se ao se expressar pela escrita e oralidade esses sujeitos reiteram seu protagonismo e coletividade, é no diálogo com esse mundo de representações proporcionado pelas diferentes leituras da palavramundo que eles encontrarão o significado existencial do homem e do diálogo no social.

Para além das ações envolvidas na escrita e expressão oral dos licenciandos, vários pontos levantados dentro do contexto da comunidade visitada e estudada puderam ser elencados para o trabalho multi e interdisciplinar nos próximos TE e TC. Nesse processo, reafirmamos que é na vivência de situações reais experienciadas pelos licenciandos que emergirão possibilidades de estudo, dentro de cada disciplina em TE, dos conteúdos disciplinares e sua integração a partir dos contextos explorados e problematizados durante o TC. 
Numa lógica propositiva de possibilidades, assuntos levantados durante 0 TC, como a produção de pimentas no assentamento visitado, podem ser problematizados para que conteúdos de Química, como o estudo das substâncias que dão pungência à pimenta e as formas de curtimento e conservação de pimentas, podem ser aliados aos estudos biológicos do manejo de pragas e identificação de insetos importantes para o processo de polinização, tomando em consideração que toda a composição contextual dessa proposta partiu das atividades de "leitura e escrita de textos".

Dessa forma, mesmo que esse exemplo tenha sido colocado de forma bastante pueril, acreditamos que esse pode ser o "gatilho" para que vários outros assuntos possam ser aprofundados nas disciplinas em TE, como: a questão ambiental do descarte de lixo, os problemas de violência sexual, os roubos e pequenos delitos dentro do assentamento, o uso da água, diversificação de culturas, a relação entre a produção familiar e o arrendamento de terras para o plantio de cana-de-açúcar. Nesta perspectiva, é importante ressaltar que a abordagem dos conteúdos nas disciplinas vem sendo amplamente discutida pelo grupo de professores da LECampo - UFTM, para que as ações multi e interdisciplinares possam, efetivamente, fazer sentido para a formação dos licenciandos, levando-se em consideração o contexto maior da vida e das vivências dentro da lógica do Campo.

\section{REFERÊNCIAS BIBLIOGRÁFICAS}

ANTUNES-ROCHA, M. I. Licenciatura em Educação do Campo: histórico e projeto político-pedagógico. In: ANTUNES-ROCHA, M. I.; MARTINS, A. A. (Orgs.). Educação do Campo: desafios para a formação de professores. Belo Horizonte: Autêntica, 2009, p. 39-55. (Coleção Caminhos do Campo; 1).

ANTUNES-ROCHA, M.I.; MARTINS, M. F. A. Tempo Escola e Tempo Comunidade: territórios educativos na educação do campo. Em: ANTUNESROCHA, M.I. (Org). Territórios educativos na educação do campo: escola, comunidade e movimentos sociais. Belo Horizonte: Autêntica, 2012, p. 21-36. 
BAGNO, M. Preconceito linguístico: o que é, como se faz. 51. ed. São Paulo: Loyola, 2009.

BORTONI, S. M. Variação linguística e atividades de letramento em sala de aula. In: KLEIMAN, A. B. (Org.). Os significados do letramento: uma nova perspectiva sobre a prática social da escrita. 10 ${ }^{\mathrm{a}}$ reimpr. Campinas, SP: Mercado de Letras, 2008, p. 119-143.

FREIRE, P. Concientizacion: teoria y practica de la liberacion. Buenos Aires: Ediciones Busqueda, 1974.

Pedagogia do oprimido. 12. ed. Rio de Janeiro: Paz e Terra, 1983.

A importância do ato de ler. In: FREIRE, P. A importância do ato de ler:

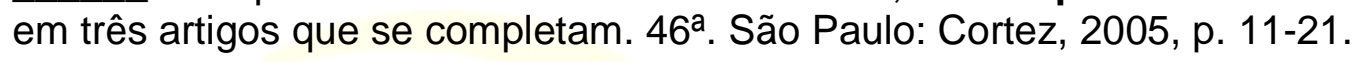

MOLINA, M. C.; SÁ, L. M. (Orgs.). Licenciaturas em Educação do Campo: registros e reflexões a partir das experiências-piloto (UFMG; UnB; UFBA e UFS). Belo Horizonte: Autêntica, 2011. (Coleção Caminhos do Campo; 5).

SCHLICKMANN, M. S. P. As cartilhas no processo de alfabetização. Linguagem em (Dis)curso, Florianópolis, v. 2, n. 1, jul./dez. 2001. Disponível em:

$<$ http://www.portaldeperiodicos.unisul.br/index.php/Linguagem Discurso/article/vie w/201/229>. Acesso em: 09 dez. 2014.

SOUZA, A.G.; CLEPS JR., J. Expansão da cana-de-açúcar no Triângulo Mineiro e os efeitos sobre a agricultura familiar e o trabalho rural. Tópos, Presidente Prudente, v.3, n.2, p. 8-35, 2009. 